\title{
Exploring Edward Said's Journalistic Collocations in Al-Ahram Weekly Newspaper: A Corpus-Based Approach
}

\author{
Amir H. Y. Salama ${ }^{1,2}$ \& Waheed M. A. Altohami ${ }^{1,3}$ \\ ${ }^{1}$ Department of English, College of Science and Humanities in Al-Kharj, Prince Sattam Bin Abdulaziz \\ University, Saudi Arabia \\ ${ }^{2}$ Department of English, Faculty of Al-Alsun (Languages), Kafr El-Sheikh University, Egypt \\ ${ }^{3}$ Department of Foreign Languages, Faculty of Education, Mansoura University, Egypt \\ Correspondence: Amir Salama, Department of English, College of Science and Humanities in Al-Kharj, Prince \\ Sattam Bin Abdulaziz University, Al-Kharj (11942), Saudi Arabia. E-mail: amir.salama79@gmail.com
}

\author{
Received: September 9, 2019 Accepted: October 8, 2019 Online Published: November 12, 2019 \\ doi:10.5539/ijel.v9n6p431 URL: https://doi.org/10.5539/ijel.v9n6p431
}

\begin{abstract}
This paper explores Edward Said's journalistic collocations as a discursive practice of the social actors that Said frequently referred to in Al-Ahram Weekly newspaper. Towards this end, a corpus-based approach has been utilized in a methodological synergy that combines the corpus techniques of extracting keywords and calculating collocations as well as the qualitative method of analysing social-actor representations (Van Leeuwen, 1996, 2008). The data used for analysis comprise a corpus of virtually all the articles written by Said in Al-Ahram Weekly from 1998 till 2003. The corpus is 105,031words and has been electronically manipulated by the corpus software tools of Wmatrix (Rayson, 2003) and WordSmith (Scott, 2012). The paper has reached three findings. First, Said's journalistic discourse in Al-Ahram Weekly revolves around 38 social-actor keywords that reflect his thematic foci all through the time span he was writing articles for the newspaper. Second, of all these keywords, only twelve node words have been identified to associate with peculiar collocates; the node words were divided into (1) nominations of political personas and (2) genericizations with various discourse functions. Third, Said's peculiar collocations reflected his ideological orientations towards certain political personas and specific topics in his journalistic discourse.
\end{abstract}

Keywords: Al-Ahram Weekly, collocations, corpus linguistics, Edward Said, social actors, Wmatrix, WordSmith

\section{Introduction}

The Palestinian-American critic and academic Edward Said (1935-2003) has been celebrated worldwide for his style of writing, be it academic or journalistic. Said was commissioned to write a column in the Egyptian newspaper of Al-Ahram Weekly, issued in English, over the time period between 1998 and 2003. One of the stylistic features that can readily be observed in Said's journalistic style is his unique usage of collocations (or at least, lexical associations) that reflect certain political representations and evaluations. Even so, thus far, there has been no systematic research on the discursively subtle meanings underlying such usage of collocations or lexical associations in Said's journalistic discourse (see Section 2).

Arguably, the linguistic phenomenon of collocation was brought to light with John Firth's (1957) famous declaration that "you shall know a word by the company it keeps" (p. 179). Thereupon this declaration, Firth has put forward the technical term "meaning by collocation" (p. 194). Since then, the term has been investigated from various approaches. One of those early approaches has been influenced by the psychological aspect of collocability, with a focus on the "collocative meaning" as comprising the typical associations of lexical items (co-)occurring in their environments (Leech, 1974, p. 20; Halliday \& Hasan, 1976, p. 287). Another approach to collocation meaning has been text-linguistically oriented. A pioneering study that presented this approach was initiated by Sinclair (1991), where collocation is defined as "the occurrence of two or more words within a short space of each other in a text" (Sinclair, 1991, p. 170). Indeed, it was Stubbs who began to develop Sinclair's notion of text-linguistic collocation into a fully-fledged corpus-based frame of investigation; this has been empirically feasible by means of Stubbs' (2001) frequency-bound formal node-collocate structure across various 
spans in textual corpora: "A 'collocate' is a word-form or lemma which co-occurs with a node in a corpus. Usually it is frequent co-occurrences which are of interest, and corpus linguistics is based on the assumption that events which are frequent are significant" (Stubbs, 2001, p. 29).

Rather than being restricted to investigating the general language of newspapers-topically or thematically - by means of corpus-based methods, the present context of research attempts to reveal the journalistic ideology of a certain professional writer, that is, Edward Said. The current study hypothesizes that using the corpus techniques of extracting keywords, calculating their peculiar collocates, and concordancing as well as the discourse approach of social-actor representations can reflect the ideological stance adopted by Edward Said in his journalistic writings in Al-Ahram Weekly newspaper. Towards (dis)proving this hypothesis, the following research questions need to be addressed: (1) What are the social-actor keywords used by Edward Said in his journalistic writings in Al-Ahram Weekly? (2) How can the peculiar collocates of these keywords be calculated? (3) To what extent do Said's peculiar collocations reflect his ideological stance in his discourse of Al-Ahram Weekly?

The remainder of the present paper is divided into six sections. Section 2 surveys the literature relevant to corpus-based research on the language of newspapers. Section 3 demonstrates how collocability is investigated in corpus linguistics with a focus on the collocation statistics of MI and $t$-score. Section 4 presents the theoretical relationship between the node-word collocation structure and social-actor representations in discourse. Section 5 outlines the methodology adopted in current research in terms of the data used for analysis and the procedure followed in conducting the analysis. Section 6 offers the analysis of collocations in relation to their potential social-actor representations in the journalistic discourse of Said. Section 7 closes the study with a summary of the main research point and the important findings coming therefrom.

\section{Review of Literature}

Stubbs' (2001) corpus-based approach to collocation has proven practically useful in achieving what Firth refers to as "the test of collocability" (Firth, 1957, p. 194). In other words, Stubbs paid due attention to the statistical definition of collocation: "My definition is therefore a statistical one: 'collocation' is frequent co-occurrence" (Stubbs, 2001, p. 29). With this definition, the different types of collocation statistics have increasingly become a yardstick against which significantly collocating pairs have been tested; and, as such, the analyst's bias has been minimized in such a way that a whole plethora of studies offered empirically tested collocations with typical discourse prosodies - be they negative or positive - associated with certain discursive practices. This type of research has been especially conducted on the language of newspapers.

By way of illustration, Mahlberg (2007) reports Tribble's (2006) significant study as examining Guardian texts by extracting keyword lists with a view to identifying "which personalities dominate the news agenda over a particular period of time" (Mahlberg, 2007, p. 197). Commenting on Tribble's (2006, p. 165) identification of the keywords "Clinton, Blair, Milosevic, Bush, Clinton's, Gore, Pinochet, Netanyahu, Putin, Hague, Blair's" in the corpus data, Mahlberg (2007, p. 197) argues that for the period 1996-2001, investigating "the collocates of the key words can then 'sort the good guys from the baddies'," immediately before the $9 / 11$ event. Besides, analysing an environmental news story, Bednarek and Caple (2012) employed frequency lists and concordance analysis of news values; similarly, the same authors proposed corpus techniques towards examining newsworthiness, but with a strict focus on the word frequency and keywords applied to a relatively small corpus of about 70,000 words (Bednarek \& Caple, 2014).

Indeed, the first case study on a prodigious newspaper corpus, with both synchronic and diachronic aspects of analysis, was provided by Potts et al. (2015) with the purpose of evaluating "corpus techniques that were not tested previously, in particular tagged lemma frequencies, collocation, key part-of-speech tags (POStags) and key semantic tags" (p. 154). In addition to the evaluation of these corpus-based techniques at the level of newsworthiness, Potts et al. (2015) offered insights into how the specific happening of Hurricane Katrina has been linguistically constructed in chief American newspapers. Additionally, Wasuwong (2017) adopted a multidisciplinary approach of CDA and corpus linguistics to investigate ideological bias through collocations in 300 news stories on the Syrian conflict as reported by CNN and Russia Today News Outlets (RT); Wasuwong (2017) found that the three keywords of SYRIA, AIRSTRIKERS, and KILLED and their collocating pairs revealed ideologically motivated imbalances in representing the Syrian conflict across the two sets of data.

Now, having surveyed the main corpus-based research conducted on newspaper language, it is time we shifted to discussing the burgeoning field of corpus linguistics and its close bearings on the notion of collocability. 


\section{Corpus Linguistics and Collocability}

Corpus linguistics is widely known as "the study of language based on examples of 'real life' language use" (McEnery \& Wilson, 1996/2001, p. 1). Yet, at a more concrete level, corpus-based approaches to the study of language have been characterized by four essential features: (i) "it is empirical, analyzing the actual patterns of use in natural texts"; (ii) "it utilizes a large and principled collection of natural texts," or corpus; (iii) "it makes extensive use of computers for analysis"; and (iv) "it depends on both qualitative and quantitative analytical techniques" (Biber et al., 1998, p. 4). The technical term "corpora", as used in modern linguistics, refers to "large bodies of naturally occurring language data stored on computers" (Baker, 2006, p. 1); and therefore, corpora have enabled linguists to "contextualize their analyses of language" and as such they are "very well suited to more functionally based discussions of language" (Meyer, 2002, p. 6).

McEnery and Wilson (2001, p. 17) have aptly used the metaphor of machine-corpus "marriage" in a way that illustrates the computer's ability to "search for a particular word, sequence words, or even ... part of speech in a text" as well as to retrieve all examples of this word, usually in context," in what is computationally known as "a concordance" (McEnery \& Wilson, 2001, p. 18, bold in original). These computer-based functions are enabled by what McEnery and Hardie (2012) describe as the "third-generation of concordance software," such as "WordSmith (Scott, 1996), MonoConc (Barlow 2000), AntConc (Anthony 2005) and Xaira" (p. 40). One essential function enabled by such concordance software is the generation of keyword lists, where keywords are viewed as a textual concept, i.e., those lexical items with significance in the text due to "unusual frequency in comparison with a reference corpus of some suitable kind" (Scott \& Tribble, 2006, p. 55). A reference corpus is typically larger than the corpus wherein the keywords are used, and is often "representative of a particular language variety" (Baker, 2006, p. 30).

Another function that is enabled by concordance software is collocability testing, i.e., using statistics that tests how a node word is significantly and/or strongly associated with a collocate or a set of collocates in a given corpus or text. Arguably, using corpus-based statistics of collocability is such an improvement over manual analysis (Krishnamurthy, 2000; Hunston, 2002). Evert (2009) classifies "association measures" of collocability into two major groups: "effect-size measures (MI, Dice, odds-ratio) and significance measures (z-score, t-score, simple-1l, chi-squared, log-likelihood)" (p. 1237). Both mutual information (MI) and $t$-score are argued here to be suitable association measures of relevant "aspects of collocativity" (Salama, 2011, 2012). On the one hand, collocational strength can be measured by the MI score, which can be "taken as evidence that two items are collocates" if it is " 3 or higher" (Hunston, 2002, p. 71). On the other hand, " $t$-scores tend to show high-frequency pairs [of collocation]"; and a $t$-score of " 2 or higher is normally considered to be statistically significant" (McEnery et al., 2006, pp. 56-57).

Interestingly, lexical associations with "high positive mutual information scores"-albeit producing low-frequency pairs in corpus data - tend to highlight the "more idiosyncratic collocates of a node"; and therefore these reflect instances of collocation that are "peculiar to [one] corpus" (Clear, 1993, p. 281) and further "constitute characteristic collocations" (McEnery \& Wilson, 2001, p. 86). Hence the need for the $t$-score as a criterion for measuring "the confidence with which we can claim that there is some association" (Church \& Hanks, 1990; cited in McEnery at al., 2006, p. 57).

Notwithstanding this, collocability should be taken one step further beyond the corpus-software statistics of node-collocate association, and be treated as a discursive practice whereby potential ideological meanings of collocation can be empirically identified (Salama, 2011). This can be realized should we view collocation as a recontextualized textual practice consciously made by language users towards producing some ideological effect-hence ideological collocation.

\section{Collocation and Social-Actor Representations}

At a theoretical level, we follow Sinclair's understanding of collocation as a text-linguistic term that is predicated on the three crucial concepts of "node," "span," and "collocates":

We may use the term node to refer to an item whose collocations we are studying, and we may then define a span as the number of lexical items on each side of a node that we consider relevant to that node. Items in the environment set by the span we will call collocates. (Sinclair, 1966, p. 415; emphasis in original)

Further, we entertain the conceptualization that on occasion collocation is so inseparable from ideology that there can be textual space for "ideological collocation" (Salama, 2011). One method that may be used in order to detect the ideological representations underlying the collocational relationship between a node and its potential collocates across some given span in text is Van Leeuwen's $(1996,2008)$ theory of the discursive representation 
of social actors; these social actors, being constitutive elements of a discourse, are "semantically involved in a social practice" (Salama, 2014, p. 131). Thus, viewed as a discourse participant, a node may enter into various relationships with those potential collocates in a textual practice in a way that reflects the collocation user's ideology_in our case, Said's ideology in the textual practice of writing articles in Al-Ahram Weekly as part of his journalistic discourse. By now, this is already methodologically established as collocation-based representations of social actors (Salama, 2012). Van Leeuwen (2008, pp. 35-51) offers an exhaustive typology of the discursive representations potentially associated with the social actors involved in a textual practice of some sort.

Here, we focus on those representations that have strongly featured in the corpus data, used in the current context of research, as node words with peculiar collocates. The first representation is "Genericization and Specification," where some social actors are represented by generic reference as "classes" or by specific reference as "identifiable individuals" (Van Leeuwen, 2008, p. 35). The second is "Association" (p. 39), with social actors represented as groups, e.g., by means of "circumstances of accompaniment" (with X or Y). The third is "Differentiation," i.e., constructing social actors as being differentiated "from a similar actor or group, creating the difference between the 'self' and the 'other', or between 'us' and 'them'" (p. 40). The fourth is "Nomination," with social actors represented in terms of their "unique identity" (p. 40). The fifth is "Functionalization," where social actors are represented in terms of "an activity," i.e., "something they do, for instance, an occupation or role" (p. 42). The sixth is "Personalization," where social actors can be personalized, i.e., represented as human beings with well-defined characteristics (p. 46).

Now, having covered the theoretical framework utilized for the data analysis, let us discuss the methodology adopted in the present study.

\section{Methodology}

This section is concerned with two methodological aspects, starting with a description of the research data then followed by a brief account of the procedure that details the steps taken towards analysing the data.

\subsection{Research Data}

The research data used for analysis is a specialized corpus that consists of virtually all the articles written by Edward Said in Al-Ahram Weekly from 1998 till 2003. The corpus counts 105,031words. Al-Ahram Weekly is an Egyptian newspaper that was established in 1991 and produced in English. The newspaper has had a notably wide circulation and mediate both local and global news in various media domains, viz. economics, politics, culture, sports, cuisine, and literature. The secondary set of corpus data is the BNC Sampler Written used as one of the reference corpora utilized by the corpus software of Wmatrix (Rayson, 2003). The reference corpus is 968,267 words. It has been selected as a reference corpus against which Edward Said's corpus can be compared for the sake of generating the keyword list of the specialized corpus.

\subsection{Procedure}

The methodological procedure adopted in the present study comprises two stages. The first stage runs through two phases: (i) the computational identification of the keywords appearing in Said's specialized corpus as compared against the BNC Sampler Written; these keywords have been determined based on their status as social actors in Said's journalistic discourse; (ii) the calculation of both strong and significant collocates of the relevant keywords, presented as node words, by means of the collocation statistics offered by Wmatrix, viz. MI score of 3 or higher and $t$-score of 2 or higher. It should be noted that those keywords without collocates would not be taken as node words that are amenable to further concordance qualitative analysis. The second stage is a concordance qualitative analysis of the node words and their collocates as used in their relevant contexts; the corpus software of WordSmith (Scott, 2012) has been utilized for generating the node-collocate concordances.

\section{Analysis: Edward Said's Journalistic Collocations in Al-Ahram Weekly}

The overall two-stage analysis is predicated on treating Said's journalistic collocations as a discursive practice of the social actors denoted in his articles in Al-Ahram Weekly. The first stage of analysis sets out with identifying the node-collocate structure as potentially realized through extracting the social-actor keywords running in text and calculating the strong and significant collocates associated with these keywords in Said's journalistic discourse. The second stage is focused on the concordance-based analysis of the node-collocate structures in terms of their social-actor representations in the same discourse.

\subsection{Identifying Node-Collocate Structure}

Wmatrix has identified 166 keywords in the corpus of Said's journalistic writings in Al-Ahram Weekly. But only 
keywords that stand as potential social actors in Said's journalistic discourse have been selected and exhibited in Table 1. As demonstrated in the table, these keyword social actors totalled 38 and they seem to carry various functions in terms of persons, groups, places, and time frames. Initially, this seems to suggest an ideological diversity of Said's journalistic representation of social actors. However, at this early stage of analysis, we cannot formulate definitive conclusions as to the kind of social-actor representation produced by Said in his journalistic discourse.

Table 1. Keyword social actors in Said's writings in Al-Ahram Weekly

\begin{tabular}{|c|c|c|c|c|c|c|c|}
\hline No. & Item & 01 & $\% 1$ & 02 & $\% 2$ & LL & Log Ratio \\
\hline 1 & Israel & 448 & 0.45 & 31 & $0.00+$ & 1896.29 & 7.12 \\
\hline 2 & Palestinians & 219 & 0.22 & 31 & $0.00+$ & 854.97 & 6.09 \\
\hline 3 & Arabs & 119 & 0.12 & 14 & $0.00+$ & 476.34 & 6.36 \\
\hline 4 & Iraq & 112 & 0.11 & 12 & $0.00+$ & 453.48 & 6.49 \\
\hline 5 & Arafat & 87 & 0.09 & 0 & $0.00+$ & 411.67 & 10.71 \\
\hline 6 & Palestine & 90 & 0.09 & 10 & $0.00+$ & 362.82 & 6.44 \\
\hline 7 & Israelis & 88 & 0.09 & 14 & $0.00+$ & 337.57 & 5.92 \\
\hline 8 & Sharon & 71 & 0.07 & 1 & $0.00+$ & 325.62 & 9.42 \\
\hline 9 & US & 356 & 0.35 & 1132 & $0.12+$ & 270.26 & 1.60 \\
\hline 10 & Jews & 77 & 0.08 & 31 & $0.00+$ & 240.98 & 4.58 \\
\hline 11 & America & 90 & 0.09 & 62 & $0.01+$ & 232.56 & 3.81 \\
\hline 12 & Oslo & 49 & 0.05 & 0 & $0.00+$ & 231.86 & 9.89 \\
\hline 13 & Ramallah & 14 & 0.01 & 0 & $0.00+$ & 66.25 & 8.08 \\
\hline 14 & Netanyahu & 14 & 0.01 & 0 & $0.00+$ & 66.25 & 0.08 \\
\hline 15 & Bush & 46 & 0.05 & 2 & $0.00+$ & 201.43 & 7.79 \\
\hline 16 & academics & 15 & 0.01 & 1 & $0.00+$ & 63.69 & 7.18 \\
\hline 17 & Hamas & 13 & 0.01 & 0 & $0.00+$ & 61.51 & 7.97 \\
\hline 18 & West_Bank & 41 & 0.04 & 1 & $0.00+$ & 184.75 & 8.63 \\
\hline 19 & Zionism & 37 & 0.04 & 0 & $0.00+$ & 175.08 & 9.48 \\
\hline 20 & Gaza & 40 & 0.04 & 5 & $0.00+$ & 158.86 & 6.27 \\
\hline 21 & Clinton & 33 & 0.03 & 5 & $0.00+$ & 127.57 & 5.99 \\
\hline 22 & Islam & 32 & 0.03 & 7 & $0.00+$ & 116.09 & 5.46 \\
\hline 23 & Saddam & 24 & 0.02 & 0 & $0.00+$ & 113.56 & 8.86 \\
\hline 24 & Jerusalem & 31 & 0.03 & 9 & $0.00+$ & 105.81 & 5.06 \\
\hline 25 & terrorists & 26 & 0.03 & 9 & $0.00+$ & 84.90 & 4.80 \\
\hline 26 & Holocaust & 19 & 0.02 & 1 & $0.00+$ & 82.16 & 7.52 \\
\hline 27 & Muslims & 25 & 0.02 & 12 & $0.00+$ & 74.04 & 4.33 \\
\hline 28 & PLO & 28 & 0.03 & 31 & $0.00+$ & 56.96 & 3.12 \\
\hline 29 & Egypt & 43 & 0.04 & 91 & $0.01+$ & 53.23 & 2.19 \\
\hline 30 & Zionists & 11 & 0.01 & 0 & $0.00+$ & 52.05 & 7.73 \\
\hline 31 & apartheid & 16 & 0.02 & 6 & $0.00+$ & 51.11 & 4.69 \\
\hline 32 & anti-semitism & 14 & 0.01 & 3 & $0.00+$ & 50.99 & 5.49 \\
\hline 33 & Iraqis & 9 & 0.01 & 0 & $0.00+$ & 42.59 & 7.44 \\
\hline 34 & $\mathrm{CNN}$ & 11 & 0.01 & 2 & $0.00+$ & 41.28 & 5.73 \\
\hline 35 & Hizbullah & 6 & 0.01 & 0 & $0.00+$ & 28.39 & 6.86 \\
\hline 36 & $9 / 11$ & 6 & 0.01 & 0 & $0.00+$ & 28.39 & 6.86 \\
\hline 37 & Syria & 16 & 0.02 & 22 & $0.00+$ & 28.32 & 2.81 \\
\hline 38 & Al-Qa'eda & 4 & 0.00 & 0 & $0.00+$ & 18.93 & 6.27 \\
\hline
\end{tabular}

Again, using Wmatrix, we calculated the peculiar and statistically significant collocates of each of the keywords identified in Table 1, to the exclusion of those keywords which have not attracted any collocates. Wmatrix has demonstrated a list of 18 keywords without significant collocates, namely, Arabs, Ramallah, academics, Hamas, Islam, terrorists, Holocaust, PLO, Egypt, Zionists, apartheid, anti-semitism, Iraqis, CNN, Hizbullah, 9/11, Syria, and $A l-Q a ' e d a$. Thus, these keywords are not considered for further collocation analysis, and do not appear as node words in Table 2. 
Table 2. Node words and their collocates in Said's writings in Al-Ahram Weekly (Wmatrix, 2003)

\begin{tabular}{lllll}
\hline No. & Keyword & Collocate & MI & T score \\
\hline $\mathbf{1}$ & ISRAEL & supporters & 5.88 & 2.20 \\
& & challenge & 5.73 & 2.94 \\
& & support & 4.94 & 3.06 \\
$\mathbf{2}$ & PALESTINIANS & killed & 5.61 & 2.19 \\
& & under & 4.67 & 2.35 \\
& & against & 3.45 & 2.40 \\
$\mathbf{3}$ & ARAFAT & Yasser & 9.20 & 3.99 \\
& & people & 3.22 & 2.00 \\
$\mathbf{4}$ & ISRAELIS & Palestinians & 3.90 & 2.09 \\
$\mathbf{5}$ & SHARON & Ariel & 9.20 & 2.44 \\
$\mathbf{6}$ & US & Israel & 3.99 & 3.55 \\
& & power & 3.48 & 2.04 \\
$\mathbf{7}$ & BUSH & George & 8.25 & 2.23 \\
& & administration & 8.75 & 2.44 \\
$\mathbf{8}$ & ZIONISM & American & 5.26 & 2.18 \\
$\mathbf{9}$ & SADDAM & Hussein & 10.41 & 3.46 \\
$\mathbf{1 0}$ & MUSLIMS & Arabs & 7.09 & 2.63 \\
\hline
\end{tabular}

Now, let us investigate the node-collocate relationships in their concordances with a view to teasing out their social-actor representations in the journalistic discourse of Said. This is tackled in the coming subsection.

\subsection{Collocation-Based Representations of Social Actors}

At this point, the ten node words identified with strong and significant collocates in Table 2 are recognized at two levels of social-actor representation. One is related to the highly personalized and nominated node-word social actors, specifically, proper nouns with specific references to certain political personas (subsection 6.2.1). The other is devoted to the generic node-word social actors, along with their collocates in the concordances, with certain aspects of representation highlighted, namely, association, differentiation, and functionalization (subsection $6.2 .2)$

\subsubsection{Collocational Personalization, Nomination, and Specification}

A number of the node words realized in Table 2 are remarkably personalized since they denote specific personas whose political weight can easily be recognized in Said's journalistic discourse in Al-Ahram Weekly; this may be substantiated in view of the premise that such node words are already top keywords in the corpus. These node words are ARAFAT, SHARON, BUSH, and SADDAM. Interesting about all four node words is the fact that their collocates are semantically the same type of noun, i.e., proper nouns. As such, both the node word and its collocate(s) mark a given individual that has a particular role in Said's discourse; and therefore such node-collocate structures are liable to be investigated in their respective concordances.

To begin, as demonstrated in Figure 1, the node ARAFAT collocate with the word Yasser in a way that reveals the identity of the ex-President of Palestine Yasser Arafat. Obviously at the time of writing this piece of journalism, Arafat was in office and Said was interested in him as a significant social actor. Crucially, the concordance lines reflect Said's dominant negative representation of the political persona of Arafat; this representation has consisted mainly in attributing pejorative qualities to him; for example, being indifferent to his people (line 7), being "a docile partner" (line 8), being "blind" in vision to some given fact (line 9), and showing "servile acquiescence" (line 12). 
by federal law to return $\$ 7,000$ worth of jewelry given to her by Yasser Arafat; and, according to the same official US government source, political responsibilities with regard to its people's past. When Yasser Arafat gave his ill-fated little speech at the White House ceremony in outlines of the 1982 Israeli invasion; in a memo he wrote to Yasser Arafat and Abu Jihad, he also sadly forecast the quick defeat of PLO in Israel as 'Allon Plus'. This way, even if Palestinian President Yasser Arafat declares a Palestinian state in May 1999, as he is expected to or the soul to encompass what is at stake. The only recourse for Arafat is to turn to his people, and not just the group of sycophants and , and in 1993 ended up delivering an exiled and sidelined Yasser Arafat as a docile partner with Israel in ending the Intifada, policing the there will be a Palestinian state at the end of the road are, like Yasser Arafat, blind to the fact that in all essential features this "state" has no straight from the US to Gaza, in order, apparently, to assure Yasser Arafat that he would work with the Palestinian Authority in furthering grievances and claims. With his people, and only with his people, can Arafat become not only the conscience but also the vision of the peace the Oslo accords is that, thanks to the servile acquiescence of Yasser Arafat, the damages of 30-plus years of Israeli occupation of the rest of to emerge without equivocation that Sharon was trying to kil Yasser Arafat, by bombing everything around the defiant Palestinian leader. is now 2002 and Clinton is no longer president.) It has been years since Arafat represented his people, their sufferings and cause, and like his Quite apart from his actual history of mistakes and misrule, Yasser Arafat is now being made to feel like a hunted Jew by the state of the years before (in 1995, well after the Oslo signings) to admit Yasser Arafat to the Philharmonic Hall for a concert to which everyone at the House. I recall many times during the 20 years that I knew Yasser Arafat well, trying to explain to him that this was a complex society or Israeli troops to quard and interdict their free movement. Yasser Arafat and his men, who are at least as responsible for the current

Figure 1. The collocates of the node word ARAFAT

The above instances of negative attribution to Arafat specify a certain context wherein the nomination of the ex-President of Palestine seemed to lack the required political efficacy hoped for by the Palestinian people at the time of such representation. Categorizing Arafat as such, Said is so explicit in his ideological stance to Arafat as a seemingly dysfunctional leader of the Palestinian people. This may explain why the second collocate people is integral to the current social-actor representation of Arafat, where the collocate has been reiterated three times in the overall concordance, namely, lines 7, 11, and 14.

The second node-collocate of SHARON and Ariel is presented in Figure 2, where Said nominates the political persona of Ariel Sharon as a ministerial element in the Israeli government then. In this context, Said is so critical of Sharon as a social actor mainly by means of attributing the semantically denigrating adjective egregious to him (line 1) as well as identifying him as having "spurs" (line 4). Indeed, the rest of the concordance lines associated with Ariel Sharon position his persona into an objective line of argument about the ministerial affairs in Israel and the Middle East.

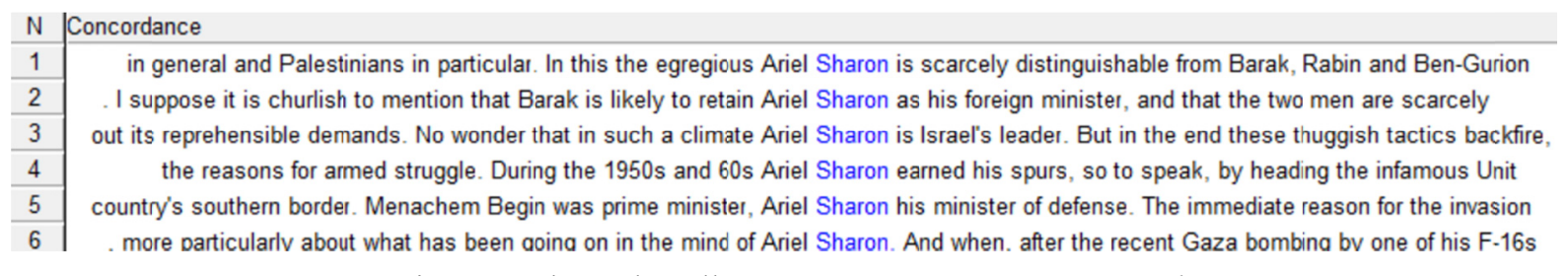

Figure 2. The node-collocate structure SHARON \& Ariel

Another nominal node-collocate structure is BUSH and George as exhibited in Figure 3. At a glance, such a nominal structure is couched into a lexical environment that is all too negative. This has been textually enabled by the words sheepishly (line 1), moronic (line 3), and irrationally (line 7); and finally the same negative representation continues with the pragmatic inference of Bush's corruption in the last line (line 8), with Bush having "spent over $\$ 200$ million to get himself elected two years ago" since the time of Said's journalistic narrative itself. Interestingly, the same negative representation textually proceeds with the other collocate of BUSH, administration, yet in a rather dominantly metaphorical expression, e.g., "... like flies on a cake" (line 4) and "... adds fuel to the fire" (line 5). Perhaps, since the collocate administration is itself less concrete than the collocate George, Said has opted for metaphorical language as a rhetorical device whereby the abstraction inherent in the social actor Bush administration becomes demystified. 


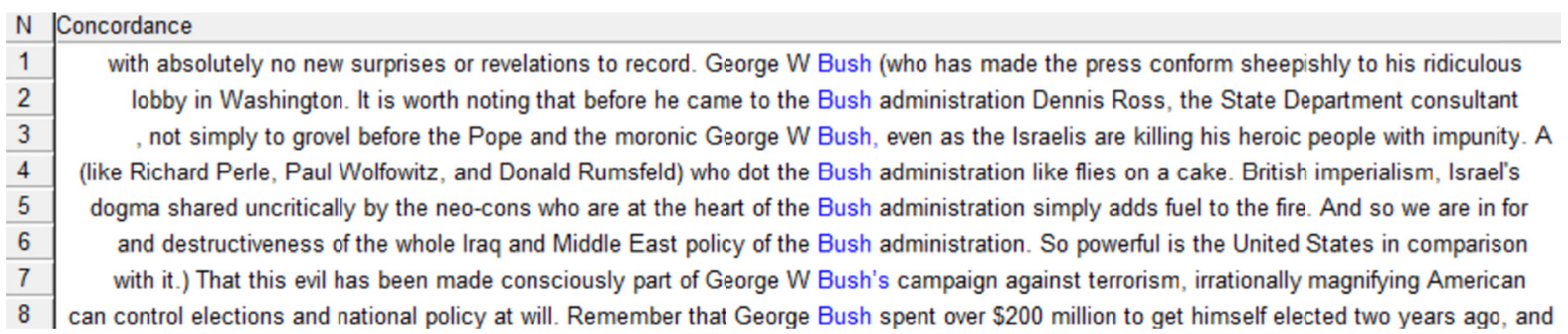

Figure 3. The collocates of the node word BUSH

Figure 4 demonstrates the last nominal node-collocate structure appearing in Said's current journalistic discourse-SADDAM and Hussein. Topically, the 2003 American war against Iraq has brought such a collocational pattern in text here. Clearly, the first concordance line makes explicit Said's personal or subjective representation of Saddam Hussein: "I am not going to even bother here add my condemnations of Saddam Hussein as a dreadful person." The second line immediately specifies the social actor of Hussein as an invader of Kuwait; and with this revelation consciously made, Said puts forward some justification for his personal representation of the given nominated social actor. The same aspect of justification continues rather argumentatively in the third line that connects Hussein with "Al-Qa'eda", and then comes the next line with the attribution of criminality expressed assertively by Said's advisedly chosen and intensified attribute incriminated: “... he will be so incriminated with having ..." (line 4). Still, the last two lines reflect Said's attitude towards Hussein who is constructed both in the lexical vicinity of Osama Bin Laden (line 5) and as a tyrant (line 6).

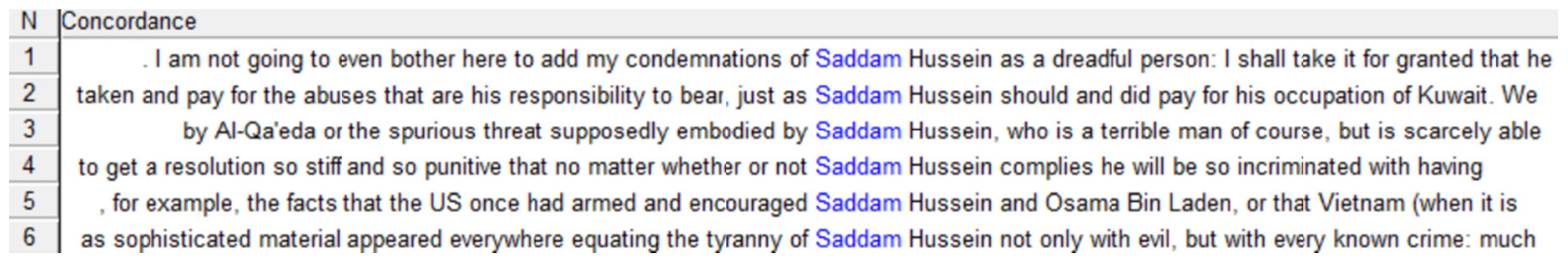

Figure 4. The node-collocate structure of SADDAM \& Hussein

Now, in the coming subsection, let us move to the second aspect of collocation-based representation of social actors in Said's discourse, with a focus on other aspects of journalistic representation.

\subsubsection{Collocational Genericization, Association, Differentiation, and Functionalization}

Again, turning back to Table 2, one can recognize a total of six node words which can initially be categorized as genericized social actors, compared to the previous section where only nominated and highly specific actors hold sway. The former social-actor node words are ISRAEL, PALESTINIANS, IRAQ, ISRAELIS, US, ZIONISM, and MUSLIMS. In what follows, we take each aside for concordance-based analysis.

The first node word ISRAEL appears in collocation with the items supporters, challenge, and support in Figure 5. The social-actor representation of Israel here looks as though there were two forces pulling apart its existence; one is related to the US supporters/support and the other to some aspect of challenge; and both forces have already been established as facts by Said, who of course reiterates their uses as collocates in his discourse. This brings in classifications of some sort: Israel as being supported by the US and Israel as being politically challenged. Perhaps the latter classification comes in close relation to the Arab countries. This assumption has already been insinuated in line 3 wherein Said precisely defines the political nature of the challenge: "The challenge of Israel is the challenge of our own societies." What is interesting and crucial in such representation is Said's highly affirmative tone about the US or American support of Israel (e.g., lines 8 and 9). Thus, the social actor of Israel is presented in association with another social actor, that is, the US. This should take us to the node word US as a social actor. 


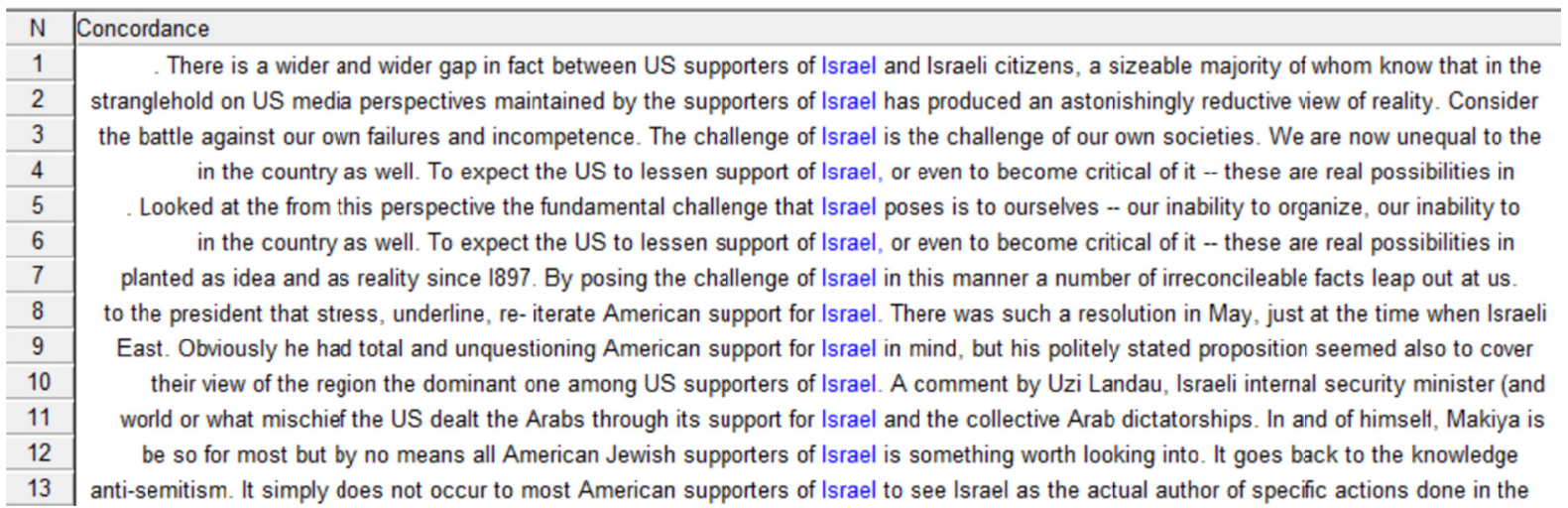

Figure 5. The collocates of the node word ISRAEL

The node word US is displayed in Figure 6 as strongly collocating with Israel. The lexical pattern is dominantly realized by the conjunctive element of "and" (lines 4, 5, 6, 7, and 8). This should cast light on the participant relation of association where one social actor seems to be textually inseparable from the other. The other collocate of US, power, effects the element of abstraction in representing the social actor US since the lexical item power is too general in reference, probably including all different aspects of power, e.g., economic, political, military, and otherwise. It is through this kind of power that the social actor of Israel has been supported and thus accorded political advantages over the Palestinian side in the Middle-East conflict. At this point, we may shift to the node word PALESTINIANS.

oncordance

this supposed to accomplish, and what does it say to the world about US power? This is a frightening message bearing no relationship to the leader. Anyone who knows anything about either Israel or the US will tell you that such tricks are absolutely useless; they may gain plainly evident in the calamitous recent history of our dealings with the US and Israel during the period since the Oslo accords were signed sectors, who roundly proclaim their enmity towards Israel and the US while in fact either collaborating with them politically and like a supplicant in trying to re-open negotiations with Israel and the US. The same things can be said about the Arab regimes and even peace with injustice rankling in every Palestinian breast. Israel and the US are too strong for him to take on alone and, since he has about the past, spending his time instead thanking Israel and the US -- his most determined persecutors - for their kindness. It was a of turning Palestinians into Red Indians being prepared for us by the US and Israel and to a great extent also by our uncomprehending and of them are generally in favor of somehow harming either Israel or the US. On the other hand, Israel and the US are widely perceived in the ot, and what besides Saddam it contains) destined for the exercise of US power unleashed illegally as a way of cowing the entire world in its the world where the main problem is, to put it as plainly as possible, US power. But at what cost, and to what end? The daily hemorrhage spreads, more unrest is almost certain: far from closing things down, US power is likely to stir them up in ways that may not be containable.

Figure 6. The collocates of the node word US

As shown in Figure 7, the node word PALESTINIANS lends itself perfectly to the social-actor representation of identification, where the word Palestinians reflects the identity of certain people as belonging to Palestine. Here comes the role of the collocating words killed, under, and against. In all three instances of collocation, the social actor Palestinians is constructed as being a victim in the same Middle-East conflict. For example, it is consistently represented as an object of killing (lines 2, 4, 9, 10,11, and 13); further, the self-same social actor is lexically featured in the pattern "under occupation" (lines 6, 7, and 14); and finally, it is used as an object of the attitudinal preposition "against" (lines 1, 8, and 12). Of course, here, Said's ideology of empathy towards the Palestinian party to the conflict is so textually explicit as to reflect some antipathy towards the Israeli and American parties in the same conflict. This may be expected should we consider the fact that Said himself is half-Palestinian in nationality. 


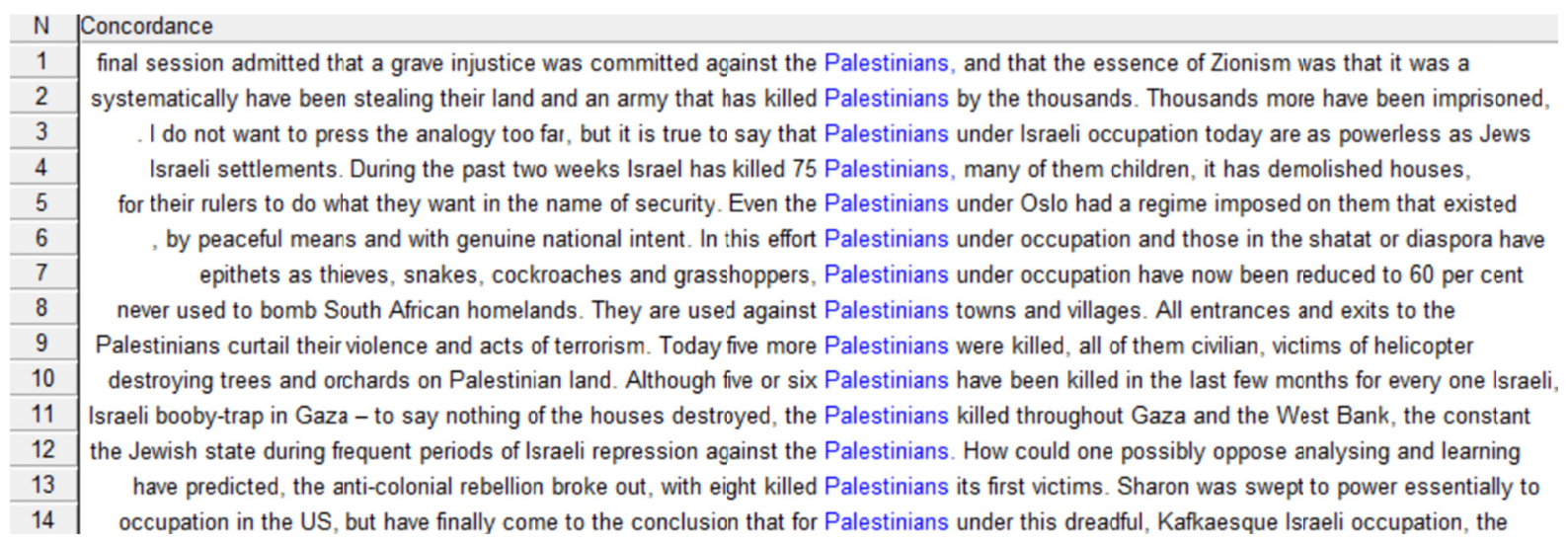

Figure 7. The collocates of the node word PALESTINIANS

Indeed, Said's political vision to the conflict between Israelis and Palestinians can be traced at the textual level of representing the social actor ISRAELIS, taken as a node word that collocates with the item Palestinians itself in Figure 8 in a way that yields the lexically dominant patterns Israelis and Palestinians and Palestinians and Israelis. As obviously demonstrated in the concordance lines, in either collocation pattern the relationship is that of association. Both social actors are not only strongly collocating but they form a conjoined unit that is semantically understood to be a single entity. This meaning of social-actor association is even expressed when Said uses the disjunctive - rather than conjunctive - form "nor": “... neither Israelis nor Palestinians have any alternative to sharing a land ..." (line 8). Here, Said emphasizes his long-standing resolution to the Palestinian-Israeli conflict, that is, sharing the same land. As such, "nor" has the discursive function of sustaining the association between the two social actors of Israelis and Palestinians.

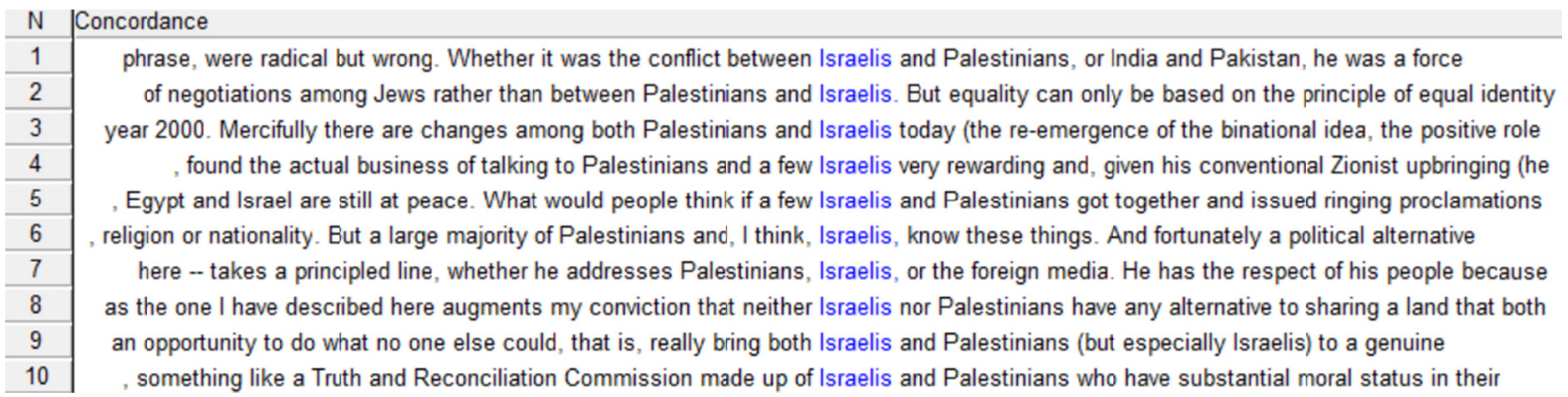

Figure 8. The node-collocate structure of ISRAELIS \& Palestinians

There is yet another type of social-actor association that can be observed between the node MUSLIMS and its collocate Arabs in Figure 9. Likewise, this aspect of association has been textually enacted by the conjunction marker "and"; the pattern is realized in one of two lexical formulas, either Muslims and Arabs or Arabs and Muslims. One significant aspect here is the ideological affinity holding between the social actors Palestinians on the one hand and the associated actors of Muslims and Arabs on the other (lines 1 \& 3). Another significant aspect is the ideological opposition reflected by the differentiation established between the associated social actors America and Israel on the one hand and the associated actors Arabs, Muslims, and Palestinians on the other (line 3); the same aspect of differentiation can be recognized between Arabs and Muslims on the one hand and Americans on the other. 


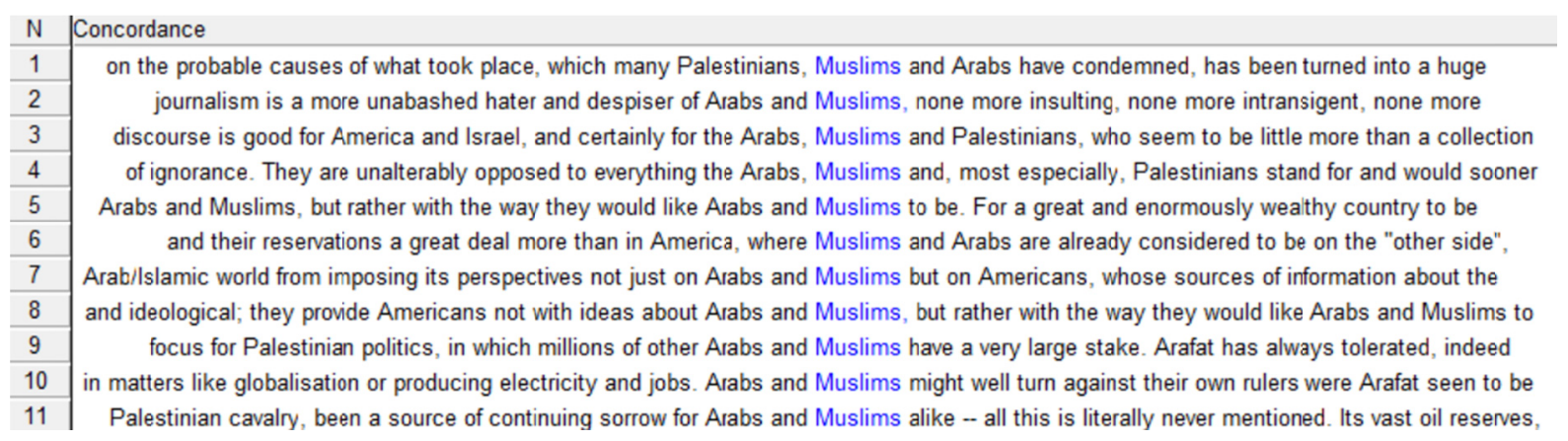

Figure 9. The node-collocate structure of MUSLIMS \& Arabs

The last node-collocate structure of ZIONISM and American appears in Figure 10 in a way that establishes the social-actor representation of functionalization; this can readily be observed in the concordance lines wherein American Zionism is linked to some sort of activities: (a) having achieved some coincidence (line 1), (b) being doomed to some results (line 2), (c) being taken on and made to change (line 3), (d) being organized in some way (line 4), and (e) having reached some level of performance (line 5). All in all, then, the representation of the social actor American Zionism is bound to certain acts that are being done or performed in Said's current journalistic discourse.

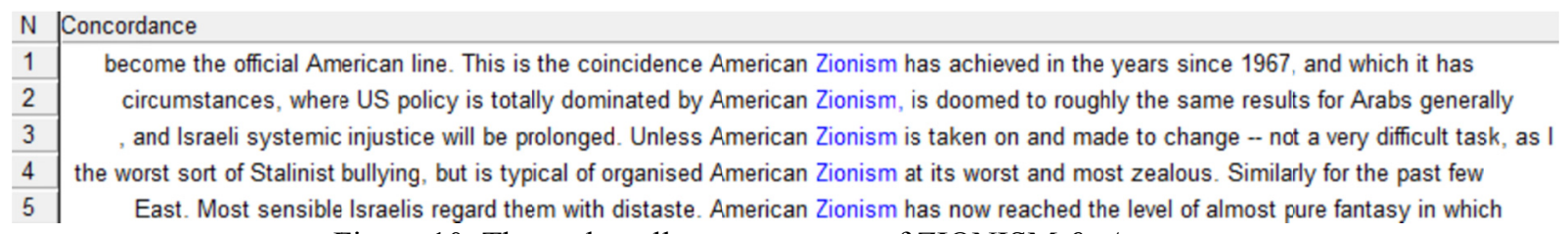

Figure 10. The node-collocate structure of ZIONISM \& American

Crucially, even though such functionalization seems to be abstract in nature-mainly by using generic terms such as coincidence, results, and level - this type of representation is significant in that it reflects Said's ideology towards America itself: being led by the Zionist Lobby. This meaning is already made explicit in the second line: “... where US policy is totally dominated by American Zionism” (line 2).

\section{Conclusion: Summary and Findings}

The present study proposed a corpus-based approach towards exploring Edward Said's journalistic collocations in Al-Ahram Weekly newspaper. The approach synergizes the corpus methods of extracting keywords and calculating collocations as well as the qualitative method of social-actor discourse analysis. Towards operationalizing the approach, two sets of corpus data have been used: (1) a specialized corpus (105,031 words) of all the articles written by Said in the newspaper from 1998 till 2003; (2) the BNC Sampler Written (968,267 words) as a reference corpus against which the specialized corpus is compared for generating the keywords in the latter.

The corpus-based analysis has methodologically proceeded at two stages. The first stage is purely quantitative in nature, and is confined to (a) the identification of the social-actor keywords frequently referred to by Said in his journalistic discourse and (b) the calculation of the strong and significant collocates of some of these keywords. Towards the fulfilment of such two-phase stage, the corpus software of Wmatrix (Rayson, 2003) has been utilized; crucially, the two collocation statistics of MI ( 3 or higher) and $t$-score ( 2 or higher) have been drawn upon in the process of calculating what has been termed peculiar collocates of social-actor keywords. The second stage is strictly qualitative, and follows Van Leeuwen's $(1996,2008)$ theory of social-actor representations. At this stage, using WordSmith (Scott, 2012), the concordance-based analysis of the collocations has been conducted in a way that reveals how each node word has been represented in Said's discourse in its collocational environment.

The study has reached three findings, with each finding addressing one of the research questions posed in the introduction (Section 1). Addressing the first research question of what the social-actor keywords used by Edward Said in his journalistic writings in Al-Ahram Weekly are, Wmatrix identified 38 keywords; these minutely reflected the main themes topically handled by Said in his writings in Al-Ahram Weekly across the time span between 1998 and 2003 (see Subsection 6.1). Tackling the second research question of how the peculiar collocates of these 
keywords can be calculated, the same corpus tool of Wmatrix has generated the items collocating with some of the keywords identified earlier. Only ten keywords have proven to be node words with peculiar collocates in Said's discourse, namely, ISRAEL, PALESTINIANS, ARAFAT, ISRAELIS, SHARON, US, BUSH, ZIONISM, SADDAM, and MUSLIMS.

In order to address the third question of how Said's peculiar collocations reflect his ideological stance in his discourse of Al-Ahram Weekly, the above node words, alongside their peculiar collocates, have been analysed in their concordances in terms of their social-actor representations. The nominal references to ARAFAT, SHARON, BUSH, and SADDAM have all revealed Said's negative representations of such political personas. Said's ideology towards each of these personas has been made explicit in text by means of the two social-actor representations of specification and personalization: Said made specific references to these social actors in well-defined contexts, and has been personally involved in expressing his own evaluations of the personas. Regarding the second set of node words-ISRAEL, PALESTINIANS, ISRAELIS, US, ZIONISM, and MUSLIMS - Said's ideological stance has been more complex and subtler. The collocational environments of such node words have unclosed certain social-actor representations: first, the association between the social actors Israel and US/America on the one hand and the social actors Palestinians, Israelis, and Arabs on the other; second, as a continuation of first, the differentiation holding between the two groups, with an ideological divide delineated and highlighted by Said; third, the association between Palestinians and Israelis as an indication of Said's long-standing vision of a two-state solution to the Palestinian-Israeli conflict; fourth, the functionalization pertinent to the social actor American Zionism as highly active participant in running the political affairs inside the US.

Besides the above social-actor representations of the node-collocate structures in Said's journalistic discourse, there appeared the collocational profiles of both Palestinians and Israelis: the former as victims being killed, under occupation and the object of attitudinal "against"; the latter as being empowered by US/American support and supporters. Thus, we are now in a position to assume that Said's collocations-which are journalistic in the current context of research - have revealed his ideology as a writer in Al-Ahram Weekly: Said has been simply and mainly concerned with the Palestinian-Israeli conflict and the role of the US actively played therein. Not surprisingly so if one carefully considers Said's early publication of The Question of Palestine (1979).

\section{Acknowledgements}

This project was supported by the Deanship of Scientific Research at Prince Sattam Bin Abdulaziz University under the research project No. 2019/02/10117.

\section{References}

Anthony, L. (2005). AntConc: a learner and classroom friendly, multi-platform corpus analysis toolkit (pp. 713). In Proceedings of IWLeL 2004: An Interactive Workshop on Language e-Learning. Tokyo: Waseda University.

Baker, P. (2006). Using corpora in discourse analysis. London: Continuum.

Barlow, M. (2000). MonoConc Pro. Houston, TX: Athelstan.

Bednarek, M., \& Caple, H. (2012). 'Value added': Language, image and news value. Discourse, Context \& Media, 1, 103-113. https://doi.org/10.1016/j.dcm.2012.05.006

Bednarek, M., \& Caple, H. (2014). Why do news values matter? Towards a new methodological framework for analyzing news discourse in critical discourse analysis and beyond. Discourse \& Society, 25(2), 135-158. https://doi.org/10.1177/0957926513516041

Biber, D., Conrad, S., \& Reppen, R. (1998). Corpus linguistics: Investigating language structure and use. Cambridge: Cambridge University Press. https://doi.org/10.1017/CBO9780511804489

Church, K., \& Hanks, P. (1990). Word association norms, mutual information and lexicography. Computational Linguistics, 16(1), 22-29. https://doi.org/10.3115/981623.981633

Clear, J. (1993). From Firth principles: computational tools for the study of collocation. In M. Baker, G. Francis \& E. Tognini-Bonelli (Eds.), Text and technology: In honour of John Sinclair (pp. 271-292). Philadephia, Amsterdam: Benjamins. https://doi.org/10.1075/z.64.18cle

Evert, S. (2009). Corpora and collocations. In A. Lüdeling \& M. Kytö (Eds.), Corpus linguistics: An international handbook (pp. 1212-1248). Vol. 2. Berlin: Walter de Gruyter.

Firth, J. (1957). Papers in linguistics, 1934-1951. Oxford: Oxford University Press. 
Halliday, M. A. K., \& Hasan, R. (1976). Cohesion in English. London: Longman.

Hunston, S. (2002). Corpora in applied Linguistics. Cambridge: Cambridge University Press. https://doi.org/10.1017/CBO9781139524773

Krishnamurthy, R. (2000). Collocation from silly ass to lexical sets. In C. Heffer, H. Sauntson \& G. Fox (Eds.), Words in context: A tribute to John Sinclair in his Retirement. Birmingham: Birmingham University Press

Leech, G. N. (1974). Semantics. Harmondsworth: Penguin.

Mahlberg, M. (2007). Lexical items in discourse: Identifying local textual functions of sustainable development. In M. Hoey, M. Mahlberg, M. Stubbs \& W. Teubert (Eds.), Text, discourse and corpora: Theory and analysis (pp. 191-218). London: Continuum.

McEnery, T., \& Hardie, A. (2012). Corpus linguistics: Method, theory and practice. Cambridge: Cambridge University Press. https://doi.org/10.1017/CBO9780511981395

McEnery, T., \& Wilson, A. (1996, 2001). Corpus linguistics: An introduction. Edinburgh: Edinburgh University Press.

McEnery, T., Xiao, R., \& Tono, Y. (2006). Corpus-based language studies: An advanced resource book. New York: Routledge.

Meyer, C. (2002). English corpus linguistics: An introduction. Cambridge: Cambridge University Press. https://doi.org/10.1017/CBO9780511606311

Potts, A., Bednarek, M., \& Caple, H. (2015). How can computer-based methods help researchers to investigate news values in large datasets? A corpus linguistic study of the construction of newsworthiness in reporting on Hurricane Katrina. Discourse \& Communication, 9(2), 149-172. https://doi.org/10.1177/1750481314568548

Rayson, P. (2003). Matrix: A statistical method and software tool for linguistic analysis through corpus comparison. Ph.D. thesis, Lancaster University.

Said, E. (1979). The question of Palestine. New York: The New York Times Book.

Salama, A. H. Y. (2011). Ideological collocation and the recontexualization of Wahhabi-Saudi Islam post-9/11: A synergy of corpus linguistics and critical discourse analysis. Discourse \& Society, 22(3), 315-342. https://doi.org/10.1177/0957926510395445

Salama, A. H. Y. (2012). The rhetoric of collocational, intertextual and institutional pluralization in Obama's Cairo speech: a discourse-analytical approach. Critical Discourse Studies, 9(3), 211-229. https://doi.org/10.1080/17405904.2012.688296

Salama, A. H. Y. (2014). Whose face to be saved? Mubarak's or Egypt's? A pragma-semantic analysis. Pragmatics and Society, 5(1), 128-146. https://doi.org/10.1075/ps.5.1.06sal

Scott, M. (1996). WordSmith Tools. Oxford University Press.

Scott, M. (2012). WordSmith Tools (Version 6.0). Oxford: Oxford University Press.

Scott, M., \& Tribble, C. (2006). Textual patterns: Keyword and corpus analysis in language education. Amsterdam: Benjamins. https://doi.org/10.1075/scl.22

Sinclair, J. (1991). Corpus, concordance, collocation. Oxford: Oxford University Press.

Stubbs, M. (2001). Words and phrases: Corpus studies of lexical semantics. Oxford: Blackwell.

Tribble, C. (2006). What counts in current journalism. Keywords in newspaper reporting. In M. Scott \& C. Tribble (Eds.), Textual patterns: Key words and corpus analysis in language education (pp. 161-177). Amsterdam: John Benjamins.

Van Leeuwen, T. (1996). The representation of social actors. In C. R. Caldas-Coulthard \& M. Coulthard (Eds.), Texts and practices: Readings in critical discourse analysis (pp. 32-70). London: Routledge.

Van Leeuwen, T. (2008). Discourse and practice: New tools for critical discourse analysis. New York: Oxford University Press. https://doi.org/10.1093/acprof:oso/9780195323306.001.0001

Wasuwong, C. P. (2017). The study of ideological bias through collocations in Syrian conflict news from CNN and Russia Today news outlets. Unpublished master's thesis dissertation. Thammasat University, Bangkok, Thailand. 


\section{Copyrights}

Copyright for this article is retained by the author, with first publication rights granted to the journal.

This is an open-access article distributed under the terms and conditions of the Creative Commons Attribution license (http://creativecommons.org/licenses/by/4.0/). 